\title{
Virus and siderophore-mediated transfer of available Fe between heterotrophic bacteria: characterization using an Fe-specific bioreporter
}

\author{
Cécile E. Mioni ${ }^{1,2, *}$, Leo Poorvin ${ }^{1, *}$, Steven W. Wilhelm ${ }^{2, * *}$ \\ ${ }^{1}$ The Department of Microbiology, and ${ }^{2}$ The Center for Environmental Biotechnology, The University of Tennessee, \\ 1414 West Cumberland, Knoxville, Tennessee 37996 0845, USA
}

\begin{abstract}
Although marine chemists can accurately quantify both the concentration of dissolved iron (Fe) and the high-affinity organic ligands which complex Fe in surface waters, tools to characterize the relative bioavailability of such organically bound Fe complexes remain unavailable. In this study, we compared the bioavailability of Fe released from the lysis of the heterotrophic bacterium Vibrio natriegens PWH3a to that of Fe complexed to synthetic chelators (EDTA) and siderophores (including the trihydroxamate desferrioxamine B [DFB] and 2 catecholates isolated from Fe-limited heterotrophic bacterial cultures) using a heterotrophic bioluminescent reporter of Fe availability (Pseudomonas putida FeLux). Using the bioluminescent response of $P$. putida FeLux, we were able to rank the Fe sources tested here in a decreasing order of bioavailability: lysates > Fe-homologous catecholate (from a P. putida FeLux culture) Fe-exogenous catecholate (from $V$. natriegens culture) $>$ inorganic $\mathrm{Fe}\left(\mathrm{FeCl}_{3}, 15 \mathrm{nM}\right) \sim \mathrm{Fe}(\mathrm{III})$ ' from EDTA-buffered treatment (pFe 18.12) > Fe:DFB, where $\mathrm{pFe}$ is $-\log \left[\mathrm{Fe}^{3+}\right]$. Combined with estimates of Fe assimilation of ${ }^{55} \mathrm{Fe}$-labeled lysates, our data further demonstrate that organic Fe complexes released during virus-mediated cell lysis are ca. 1000 times more bioavailable and efficiently assimilated by bacterial cells than Fe(III)'. Our results validate the utilization of $P$. putida FeLux as a bioreporter of Fe-bioavailability and also support the assumption that virus activity plays a crucial role in the regeneration of biologically available Fe complexes in surface seawater.
\end{abstract}

KEY WORDS: Iron availability · Bioreporter · Heterotrophic bacteria $\cdot$ Siderophore $\cdot$ Virus lysates - Resale or republication not permitted without written consent of the publisher

\section{INTRODUCTION}

A number of independent studies have clearly demonstrated that approximately half of the world's oceans are chronically or seasonally Fe-deplete (Moore et al. 2004). This growth-limiting concentration of Fe has been suggested to control phytoplankton production (Boyd 2004). Most (>99\%) of the dissolved Fe in these regions is complexed by strong organic ligands, leaving less than $0.1 \mathrm{pmol} \mathrm{kg}^{-1}$ as free ferric species (Rue \& Bruland 1995, Wu \& Luther 1995). Over the past decade, several studies have demonstrated that organic complexation can control Fe concentration and Fe speciation and thus its bioavailability to marine plankton (Gledhill \& van den Berg 1994, Wu \& Luther 1995, Boye et al. 2001). Although uncertainties remain regarding the source(s) and chemical structure of these organic ligands, it appears that they fall into 2 distinct classes: a strong (L1) and a weak (L2) ligand class. It is currently assumed that L1 is actively produced by plankton resident in the water column while the weaker ligand class L2 results from both active production as well as the degradation of the L1 group (Rue \& Bruland 1995, Butler 1998, Tortell et al. 1999). Recently we have proposed that a significant component of these Fe-ligand complexes are the products of cellular mortality (Poorvin et al. 2004). While little is known about the relative bioavailability and the fate of 
these organic ligands in natural systems, recent experiments suggest that the chemical nature of these Fe complexes may influence competition between prokaryotes and eukaryotes (Hutchins et al. 1999a, Poorvin et al. 2004).

The similarities between the stability constants (Lewis et al. 1995, Rue \& Bruland 1995) and structural groups (Martinez et al. 2003, Gledhill et al. 2004) of the natural organic Fe ligands and those for naturally produced siderophores has led to a surge of interest in the microbial component of the marine plankton assemblage. It has been demonstrated that marine heterotrophic bacteria account for as much as $50 \%$ of the biomass (and thus biogenic Fe) in oceanic systems (Tortell et al. 1999). Furthermore, bacteria contain significantly more Fe per biomass unit than phytoplankton and are responsible for significant Fe uptake in Fe-depleted seawaters (Tortell et al. 1996). In addition, although several studies have shown that bacterial productivity was co-limited by carbon and Fe (Church et al. 2000, Kirchman et al. 2000), other studies suggest that heterotrophic bacterial productivity may be directly Fe-limited at low, in situ concentrations (Pakulski et al. 1996, Tortell et al. 1996). Finally, conflicting reports suggest that Fe may (Eldridge 2004) or may not (Hutchins et al. 2001, Arrieta et al. 2004) influence bacterial diversity. Although it is well established that Fe is efficiently recycled in marine surface waters, the question of how resources (bottom-up) and predation (top-down) control this process is not fully resolved.

In marine ecosystems, viruses are typically 5 to 10 times more abundant than bacteria (Weinbauer 2004) and persist at densities ranging from $<10^{4}$ to $>10^{8} \mathrm{ml}^{-1}$ (Wommack \& Colwell 2000), resulting in a global population of ca. $3.5 \times 10^{29}$ viruses in the world's oceans (Wilhelm \& Suttle 2000). Moreover, findings suggest that phages dominate the virus population in aquatic systems (Fuhrman 1999, Breitbart et al. 2002). As such, viruses may play an important role in the regeneration of organically complexed nutrients in aquatic systems (Gobler et al. 1997, Fuhrman 1999, Wilhelm \& Suttle 1999). Very little is known about the chemical nature, molecular size and bioavailability of nutrients such as Fe that are released during the phage-mediated lysis of prokaryotes. Recent laboratory experiments, using model planktonic organisms, have shown that such a viral lysis resulted in the release of a range of dissolved to particulate Fe-containing components and that this Fe can be rapidly assimilated by other plankton (Poorvin et al. 2004). Consequently, virus-mediated Fe regeneration may provide a substantial fraction of total bioavailable Fe in oceanic systems and may support as much as $90 \%$ of the primary production in recyclingbased HNLC (high nutrient, low chlorophyll) systems (Poorvin et al. 2004). In parallel, virus activity may also control prokaryotic abundance in marine systems, especially when growth conditions are favorable (Weinbauer 2004). As such, the control exerted by viruses on prokaryotic proliferation, and the subsequent destruction of cells, may explain the increase in organic ligand concentrations observed during mesoscale Fe fertilization-an event which should suppress prokaryotic siderophore production (Poorvin et al. 2004).

In this study, we hypothesized that lysates may increase Fe bioavailability by adding to the concentration and diversity of bioavailable Fe species that are, at least in part, readily available to the oceanic prokaryotes. We compared the bioavailability of Fe released from lysates of the heterotrophic bacterium Vibrio natriegens PWH3a to that of Fe complexed to a model synthetic chelator (EDTA) using a heterotrophic bioluminescent reporter for Fe availability, Pseudomonas putida FeLux (Mioni et al. 2003). This bioreporter produces a luminescent signal which is inversely correlated to Fe bioavailability. Combined with estimates of Fe assimilation from ${ }^{55} \mathrm{Fe}$-labeled lysates by the bioluminescent bacterial reporter, our data suggest that organic Fe complexes released during lysis are both highly available and efficiently assimilated by bacterial cells. The bioavailability of Fe complexed to siderophores produced by the 2 heterotrophic bacteria ( V. natriegens and P. putida) was also examined. Our data suggest that Fe complexes released from virusmediated lysis are more bioavailable than Fesiderophore complexes, and validate the use of the $P$. putida FeLux bioreporter for these studies.

\section{MATERIALS AND METHODS}

Production of virus-mediated lysates. To reduce Fe contamination, all nutrient stocks and water used in this study were treated with Chelex-100 resin (Price et al. 1988). All culture materials were soaked in dilute $\mathrm{HCl}$ and rinsed with Chelex-100-treated Milli-Q water prior to use. All manipulations were performed under class-100 conditions to maintain aseptic and tracemetal clean conditions.

Virus-mediated lysates of the heterotrophic bacterium Vibrio natriegens PWH3a were prepared as previously described (Poorvin et al. 2004). In brief, $V$. natriegens PWH3a cultures were grown in modified ESAW (enriched seawater, artificial seawater) medium (Berges et al. 2001) supplemented with glycerol and ${ }^{55} \mathrm{Fe}$ (3.33 nM total Fe concentration) at $25^{\circ} \mathrm{C}$ for $4 \mathrm{~d}$. Cells were collected by centrifugation and washed with Ti(III)-citrate-EDTA (Hudson \& Morel 1989) to remove surface-associated ${ }^{55} \mathrm{Fe}$. Cells were then resuspended in carbon-free ESAW medium supplemented with non-radioactive Fe (1 nM) and the lytic bacterio- 
phage PWH3a-P1. Bacteria cells and virus particles were incubated for $24 \mathrm{~h}$ to allow for virus infection and subsequent cell lysis. The dissolved fraction of the lysate was collected after filtration through $0.22 \mu \mathrm{m}, 47$ $\mathrm{mm}$ diameter polycarbonate filters. The final Fe concentration in the lysate was estimated at $4.33 \mathrm{nmol} \mathrm{l}^{-1}$ (3.33 $\mathrm{nM}^{55} \mathrm{Fe}$ and $1 \mathrm{nM} \mathrm{Fe}$ ).

Estimation of iron bioavailability to Pseudomonas putida FeLux. P. putida FeLux (Mioni et al. 2003) stock cultures were maintained at $30^{\circ} \mathrm{C}$ on Pseudomonas Isolation Agar (Remel) supplemented with $50 \mu \mathrm{g} \mathrm{ml}^{-1}$ of tetracycline (Tc). For each experiment an individual colony was selected and amplified to provide a stock culture for use with all treatments. Cultures from the selected colony were maintained at $25^{\circ} \mathrm{C}$ (with shaking) in microwave-sterilized (Keller et al. 1988) marine broth 2216 (Difco) supplemented with $50 \mu \mathrm{g} \mathrm{ml}^{-1}$ Tc. Bioreporter cells were acclimated in Fe-deficient bacterium growth enriched seawater, artificial seawater (BESAW) medium ( $\mathrm{pFe}$ 21.15, Mioni 2004) and incubated overnight at $25^{\circ} \mathrm{C}$ with shaking. The experiment was started by transferring $2 \mathrm{ml}$ of the overnight-acclimated cell culture to each replicate tube. All treatments were performed in triplicate. The optical density at $600 \mathrm{~nm}$ $\left(\mathrm{OD}_{600}\right)$ and light production were measured every $2 \mathrm{~h}$ over an experimental period of $12 \mathrm{~h}$ using a spectrophotometer (Biomate 5, Thermospectronic) and luminometer (FB-15, Zylux). At each time point, light production was normalized to estimated cell abundance $\left(\mathrm{OD}_{600}\right)$.

Treatments supplemented with Fe-EDTA were prepared as described elsewhere (Mioni 2004). Sterile aliquots of Fe-free BESAW (18 ml) were dispensed into acid-washed and microwave-sterilized Oakridge tubes. Fe species within the BESAW medium were determined using Mineql+ software (version 4.5, Environmental Research software). Both $\mathrm{pFe}\left(-\log \left[\mathrm{Fe}^{3+}\right]\right)$ and Fe(III)' (sum of the major inorganic Fe species) were determined for a series of total Fe concentrations so as to chemically describe the medium (Sunda \& Huntsman 2003) (Table 1). The concentration of Fe was altered to create an increasing range of modeled free $\mathrm{Fe}^{3+}$ spanning from $\mathrm{pFe} 21.15$ (Fe(III)' $=0.93 \mathrm{pM}$ ) to $\mathrm{pFe} 16.84\left(\mathrm{Fe}(\mathrm{III})^{\prime}=18.6 \mathrm{nM}\right)$. The final concentration of EDTA was maintained constant in all treatments $(100 \mu \mathrm{M})$. As previous studies have shown that Fecomplexed to EDTA is not available to Pseudomonas putida (Meyer \& Hohnabel 1992), the bioluminescent signal is assumed to be correlated to the free inorganic Fe species present in the EDTA-buffered treatments. Light production per $\mathrm{OD}_{600}$ values were converted to light production per cell using the empirically determined linear function: $y=3.459 \times 10^{8}-3.611 \times 10^{6} x$, where $y$ is the number of bioreporter cell ml- $\mathrm{m}^{-1}$ and $x$ the corresponding $\mathrm{OD}_{600}$ value. Values are the mean of triplicate cultures from the $12 \mathrm{~h}$ time-point.

Treatments amended with ${ }^{55} \mathrm{Fe}$-labeled lysate were prepared similarly to Fe-EDTA treatments. In these treatments, EDTA was omitted so that the lysate mixture was the only source of $\mathrm{Fe}$ and Fe ligands. Increasing volumes of radiolabeled lysate were added to sterile Fe-free BESAW medium (total volume = $18 \mathrm{ml}$ ) to obtain the following final total Fe concentra-

Table 1. Chemical speciation of Fe in EDTA-buffered bacterium growth enriched seawater, artificial seawater (BESAW) medium. EDTA $=100 \mu \mathrm{M}, \mathrm{pH} 7.8$ at $25^{\circ} \mathrm{C}$ and $\mathrm{FeCl}_{3} \cdot 6 \mathrm{H}_{2} \mathrm{O}$. Fe(III)' and pFe estimates are given for comparison to other lab studies only, as it is anticipated that $\mathrm{Fe}$ concentrations in the highest treatments $\left(^{*}\right)$ may result in precipitation in seawater. $\mathrm{pFe}:-\log \left[\mathrm{Fe}^{3+}\right]$; $\mathrm{Fe}(\mathrm{III})^{\prime}$ : sum of the major inorganic Fe species (pM)

\begin{tabular}{|c|c|c|c|c|c|c|c|}
\hline $\begin{array}{l}\text { Fe } \\
\text { species }\end{array}$ & $\begin{array}{rc}\text { Total Fe: } & 5.0 \times 10^{-9} \\
\text { PFe: } & 21.15 \\
\text { Fe(III)': } & 0.93\end{array}$ & $\begin{array}{c}5.0 \times 10^{-8} \\
20.15 \\
9.3\end{array}$ & $\begin{array}{c}2.0 \times 10^{-7} \\
19.54 \\
37\end{array}$ & $\begin{array}{c}5.0 \times 10^{-7} \\
19.14 \\
93\end{array}$ & $\begin{array}{c}7.5 \times 10^{-7} \\
18.97 \\
140\end{array}$ & $\begin{array}{c}5.0 \times 10^{-6} \\
18.12 \\
980\end{array}$ & $\begin{array}{c}5.0 \times 10^{-5} \\
16.84^{*} \\
18600^{*}\end{array}$ \\
\hline $\mathrm{Fe}^{3+}$ & $7.15 \times 10^{-22}$ & $7.16 \times 10^{-21}$ & $2.87 \times 10^{-20}$ & $7.19 \times 10^{-20}$ & $1.08 \times 10^{-19}$ & $7.53 \times 10^{-19}$ & $1.43 \times 10^{-17}$ \\
\hline $\mathrm{Fe}(\mathrm{OH})_{2}{ }^{+}$ & $6.94 \times 10^{-12}$ & $6.94 \times 10^{-11}$ & $2.78 \times 10^{-10}$ & $6.97 \times 10^{-10}$ & $1.05 \times 10^{-9}$ & $7.31 \times 10^{-9}$ & $1.39 \times 10^{-7}$ \\
\hline $\mathrm{Fe}(\mathrm{OH})_{3 \mathrm{aq}}$ & $3.53 \times 10^{-12}$ & $3.53 \times 10^{-11}$ & $1.41 \times 10^{-10}$ & $3.55 \times 10^{-10}$ & $5.34 \times 10^{-10}$ & $3.72 \times 10^{-9}$ & $7.07 \times 10^{-8}$ \\
\hline $\mathrm{Fe}(\mathrm{OH})_{4}$ & $2.80 \times 10^{-13}$ & $2.80 \times 10^{-12}$ & $1.12 \times 10^{-11}$ & $2.81 \times 10^{-11}$ & $4.23 \times 10^{-11}$ & $2.95 \times 10^{-10}$ & $5.61 \times 10^{-9}$ \\
\hline $\mathrm{Fe}(\mathrm{OH})^{2+}$ & $6.77 \times 10^{-17}$ & $6.77 \times 10^{-16}$ & $2.71 \times 10^{-15}$ & $6.80 \times 10^{-15}$ & $1.02 \times 10^{-14}$ & $7.13 \times 10^{-14}$ & $1.36 \times 10^{-12}$ \\
\hline $\mathrm{Fe}_{2}(\mathrm{OH})_{2}^{+}$ & $1.59 \times 10^{-30}$ & $1.59 \times 10^{-28}$ & $2.55 \times 10^{-27}$ & $1.60 \times 10^{-26}$ & $3.62 \times 10^{-26}$ & $1.76 \times 10^{-24}$ & $6.36 \times 10^{-22}$ \\
\hline $\mathrm{Fe}_{3}(\mathrm{OH})_{4}^{+}$ & $1.66 \times 10^{-39}$ & $1.67 \times 10^{-36}$ & $1.07 \times 10^{-34}$ & $1.69 \times 10^{-33}$ & $5.74 \times 10^{-33}$ & $1.94 \times 10^{-30}$ & $1.34 \times 10^{-26}$ \\
\hline $\mathrm{FeHPO}_{4}{ }^{+}$ & $1.21 \times 10^{-18}$ & $1.21 \times 10^{-17}$ & $4.87 \times 10^{-17}$ & $1.22 \times 10^{-16}$ & $1.83 \times 10^{-16}$ & $1.28 \times 10^{-15}$ & $2.43 \times 10^{-14}$ \\
\hline $\mathrm{FeH}_{2} \mathrm{PO}_{4}{ }^{2+}$ & $1.68 \times 10^{-24}$ & $1.69 \times 10^{-23}$ & $6.75 \times 10^{-23}$ & $1.69 \times 10^{-22}$ & $2.55 \times 10^{-22}$ & $1.77 \times 10^{-21}$ & $3.37 \times 10^{-20}$ \\
\hline $\mathrm{FeBr}_{2}$ & $3.55 \times 10^{-25}$ & $3.55 \times 10^{-24}$ & $1.42 \times 10^{-23}$ & $3.57 \times 10^{-23}$ & $5.37 \times 10^{-23}$ & $3.74 \times 10^{-22}$ & $7.11 \times 10^{-21}$ \\
\hline $\mathrm{FeCl}_{2}^{+}$ & $3.83 \times 10^{-22}$ & $3.83 \times 10^{-21}$ & $1.53 \times 10^{-20}$ & $3.84 \times 10^{-20}$ & $5.78 \times 10^{-20}$ & $4.03 \times 10^{-19}$ & $7.66 \times 10^{-18}$ \\
\hline $\mathrm{FeCl}_{3}$ (aq) & $5.81 \times 10^{-24}$ & $5.81 \times 10^{-23}$ & $2.33 \times 10^{-22}$ & $5.84 \times 10^{-22}$ & $8.78 \times 10^{-22}$ & $6.12 \times 10^{-21}$ & $1.16 \times 10^{-19}$ \\
\hline $\mathrm{FeCl}_{2}^{+}$ & $1.01 \times 10^{-21}$ & $1.01 \times 10^{-20}$ & $4.07 \times 10^{-20}$ & $1.02 \times 10^{-19}$ & $1.53 \times 10^{-19}$ & $1.07 \times 10^{-18}$ & $2.03 \times 10^{-17}$ \\
\hline $\mathrm{FeNO}_{3}{ }^{2+}$ & $6.70 \times 10^{-25}$ & $6.70 \times 10^{-24}$ & $2.68 \times 10^{-23}$ & $6.73 \times 10^{-23}$ & $1.01 \times 10^{-22}$ & $7.05 \times 10^{-22}$ & $1.34 \times 10^{-20}$ \\
\hline $\mathrm{FeHSeO}_{3}{ }^{2+}$ & $2.02 \times 10^{-28}$ & $2.03 \times 10^{-27}$ & $8.12 \times 10^{-27}$ & $2.04 \times 10^{-26}$ & $3.06 \times 10^{-26}$ & $2.13 \times 10^{-25}$ & $4.05 \times 10^{-24}$ \\
\hline $\mathrm{FeSO}_{4}^{+}$ & $5.78 \times 10^{-21}$ & $5.78 \times 10^{-20}$ & $2.32 \times 10^{-19}$ & $5.81 \times 10^{-19}$ & $8.73 \times 10^{-19}$ & $6.09 \times 10^{-18}$ & $1.16 \times 10^{-16}$ \\
\hline $\mathrm{Fe}\left(\mathrm{SO}_{4}\right)_{2}^{-}$ & $9.30 \times 10^{-22}$ & $9.31 \times 10^{-21}$ & $3.73 \times 10^{-20}$ & $9.35 \times 10^{-20}$ & $1.41 \times 10^{-19}$ & $9.79 \times 10^{-19}$ & $1.86 \times 10^{-17}$ \\
\hline
\end{tabular}


tions: $43.3 \mathrm{pmol} \mathrm{l}^{-1}, 0.11 \mathrm{nmol} \mathrm{l^{-1 }}, 0.16 \mathrm{nmol} \mathrm{l}^{-1}$, $0.21 \mathrm{nmol} \mathrm{l}^{-1}, 0.54 \mathrm{nmol} \mathrm{l}^{-1}$, and $4.33 \mathrm{nmol} \mathrm{l}^{-1}$. The last treatment was composed completely of lysate $(100 \%$ v/v). Chelex-100-treated glycerol was supplied directly to replicate tubes to obtain a similar carbon in all treatments. For all lysate-amended treatments, in parallel to bioluminescence and $\mathrm{OD}_{600}$ monitoring, $1 \mathrm{ml}$ of culture was fixed with glutaraldehyde $(2.50 \%$ $\mathrm{v} / \mathrm{v}$ ) at time $t=12 \mathrm{~h}$ and enumerated by epifluorescence microscopy after treatment with acridine orange (Hobbie et al. 1977) on a Leica DMRXA epifluorescence microscope.

Lysate assimilation studies. Fe-assimilate in the lysate-amended treatments was assessed as previously described (Poorvin et al. 2004). At time $t=12 \mathrm{~h}, 2 \mathrm{ml}$ of each lysate-amended treatment were collected by filtration through $47 \mathrm{~mm}$ diameter, $0.2 \mu \mathrm{m}$ nominal pore-size polycarbonate filters. Extracellular Fe was removed by washing the filters with Ti(III)-citrateEDTA (Hudson \& Morel 1989). Filters were placed into $4 \mathrm{ml}$ scintillation vials and dissolved for $1 \mathrm{~h}$ with $500 \mu \mathrm{l}$ of ethyl acetate. Scintillation fluid was added prior to the analyses of ${ }^{55} \mathrm{Fe}$. Preliminary tests demonstrated that residual bioluminescence from the bioreporters does not interfere with the results from the Wallac scintillation counter (data not shown).

Isolation of siderophores. Batch cultures (ca. 10 l) of Pseudomonas putida FeLux and Vibrio natriegens PWH3a were grown in a modified BESAW culture medium to optimize siderophore production. The medium was supplemented with $0.5 \mathrm{ml}$ of glycerol (100\%) for $V$. natriegens PWH3a and $1 \mathrm{ml}$ of glycerol $(100 \%)$ for $P$. putida FeLux. All trace metals except Fe were identical to that of ESAW medium (Berges et al. 2001). Inorganic Fe was supplemented to the medium to reach a final concentration of $1 \mathrm{nM}$. EDTA was omitted from the medium as it has been demonstrated that it reacts with siderophore assays (Granger \& Price 1999). No effort was made to limit trace-metal contamination: the culture media were not treated with Chelex-100 and were autoclave sterilized. However, all manipulations were performed with aseptic techniques. Batch cultures were grown to stationary phase at room temperature in 101 polycarbonate carboys containing a Teflon stir bar (ca. 5 d).

Deferrated siderophores were extracted from the $0.22 \mu \mathrm{m}$ filtrate of the bacterial cultures as described previously (Wilhelm \& Trick 1994, 1995). After acidification to $\mathrm{pH} 3.0$, organics in the filtrate were collected using Amberlite XAD-16 resin (BioRad). The column was allowed to dry overnight and was washed subsequently with Chelex-100-treated Milli-Q water. The organic fraction containing the siderophores was subsequently eluted with methanol. Extracts were concentrated by rotary evaporation and stored at $4^{\circ} \mathrm{C}$.
Characterization of siderophores. Extracts were assayed for Fe-binding compounds by thin layer chromatography (TLC) on cellulose plates (Merck) using methanol: $\mathrm{H}_{2} \mathrm{O}(70: 30, v / v)$ as a solvent. Fe-binding compounds were resolved by spraying the dried TLC plate with $1 \% \mathrm{FeCl}_{3}$ in ethanol (Wilhelm \& Trick 1994). To estimate the total Fe-binding capacity of these compounds, we performed the Chrome Azurol S (CAS) assay (Schwyn \& Neilands 1987). Standard curves for the CAS assay were generated with the fungal siderophore desferrioxamine B (DFB, Sigma). To determine the chemical nature of the Fe-binding compounds, we performed 2 more assays. Catecholate moieties were detected using the Rioux assay (Rioux et al. 1983) standardized with 2,3-dihydroxybenzoic acid (2,3-DHBA). The modified Csaky test was used to detect hydroxamate functional groups with DFB as a standard (Csaky 1948, Gillam et al. 1981).

Determination of the bioavailability of Fesiderophore complexes. To assess the bioavailability of the siderophore extracts, Pseudomonas putida FeLux cultures were maintained and acclimated as described above. At time zero, acclimated cells were inoculated into $18 \mathrm{ml}$ of BESAW medium supplemented with $15 \mathrm{nM} \mathrm{FeCl}_{3}$ and $5 \mathrm{nM}$ or $15 \mathrm{nM}$ (Febinding equivalents as determined by the CAS assay) of the siderophore extract. Comparisons to 2 other treatments were also made: inorganic Fe (15 nM $\mathrm{FeCl}_{3}$ ) and Fe:DFB (15 nM:5 nM). The Fe-DFB treatment was used here as a positive control as we demonstrated previously that Fe complexed to DFB is not bioavailable to the $P$. putida FeLux bioreporter (Mioni et al. 2003). Bioluminescence and bacterial density were monitored as described above. All treatments were repeated in triplicate.

To determine whether Fe bound to the fungal siderophore DFB was bioavailable to the bioreporter cells, we evaluated the impact of equimolar Fe:DFB complex additions on the bioreporter in Fe-replete medium $\left(\mathrm{FeCl}_{3}=15 \mathrm{nM}\right)$. Cells were acclimated and prepared following the same protocol described above. To insure chemical equilibrium between the added DFB and Fe(III), DFB was added using 1000-time concentrated Fe(III):DFB premixed (1:1) stock solutions. At time zero, acclimated cells were inoculated to $18 \mathrm{ml}$ of BESAW medium supplemented with $15 \mathrm{nM}$ of $\mathrm{FeCl}_{3}$ plus the Fe:DFB premix to the final concentrations of 0 (control), 5, 10, 15, and $20 \mathrm{nM}$. EDTA was omitted from the recipe. All treatments were triplicated. Assuming that the added DFB bound to Fe(III) in 1:1 ligand stoichiometry (Rue \& Bruland 1995, Liu \& Hider 2002) the total inorganic Fe concentration was $15 \mathrm{nM}$ in all treatments.

Statistical analyses. Statistical analyses were performed using SPSS (version 12) software. Independent $t$-tests (2-tailed), analyses of variance (1-way ANOVA) 
and multiple comparison tests were performed assuming equal variance of mean values. The homogeneity of variance was tested in each analysis using the Levene test. ANOVA was used to establish the statistical significances of variation among different treatments. In parallel, multiple comparison tests were performed to ascertain differences. Dunnett's test was used to analyze the significance of the variations in the means of Fe:DFB amended treatments relative to the control treatment (Corston \& Colman 2003). The Tukey's honestly significant difference test (Tukey-HSD test) was used to establish the statistical significance of variations among treatment means (Corston \& Colman 2003). Unless stated, results were considered significant at $\mathrm{p}<0.05$.

\section{RESULTS}

\section{Bioavailability of Fe released from virus-mediated lysates}

Light production by Pseudomonas putida FeLux bioreporter cells grown in the trace-metal-buffered BESAW medium was characterized by a sigmoidal function with a linear dose-response portion extending from pFe 19.54 to 16.84 (Fig. 1A). Linear regression analysis performed over the linear region using Sigma-Plot software (version 9, SPSS) yielded the equation $y=0.0271 x$ $-0.1023\left(r^{2}=0.994\right.$; where $y$ is the bioluminescent signal per cell and $x$ the $\mathrm{pFe}$ ). The luminescent signal was saturated for $\mathrm{pFe}$ values higher than 18.6 as no significant differences were observed between the treatments pFe 21.15, 20.15 and 19.54 (ANOVA, p > 0.05). The results suggest that all high-affinity transport systems were derepressed in this medium at free $\mathrm{Fe}^{3+}$ concentrations lower than $10^{-19.54} \mathrm{M}$ (ca. Fe' $=37 \mathrm{pM}$; total $\mathrm{Fe}=200 \mathrm{nM}$ in EDTA-buffered synthetic medium).

The bioluminescent response of Pseudomonas putida FeLux in treatments supplemented with increasing levels of Fe from Vibrio natriegens PWH3a lysates also followed a sigmoidal function $\left(\mathrm{r}^{2}=0.997\right.$; Fig. 1B). Light production reached a maximal level of $0.370 \pm 0.013$ relative light units (RLU) $\mathrm{s}^{-1} \mathrm{cell}^{-1}$ in treatments supplemented with 43.3 to $160 \mathrm{pM}$ Fe. No significant variations were found between these treatments (ANOVA, $p>0.05$ ). The threshold Fe concentration for a significant decrease in light production was reached in the treatment supplemented with $0.21 \mathrm{nM}$ of Fe (Tukey-HSD test, $p=0.02$ ). As such, the repression of high-affinity Fe transport systems occurred at $\mathrm{Fe}$ concentrations $\geq 0.21 \mathrm{nM}$ in lysate treatments (Figs. 1B \& 2), relative to total Fe concentrations $>200$ nM (i.e. pFe 19.54) when Fe was complexed to EDTA (Figs. 1A \& 2). This result suggests that Fe pre-
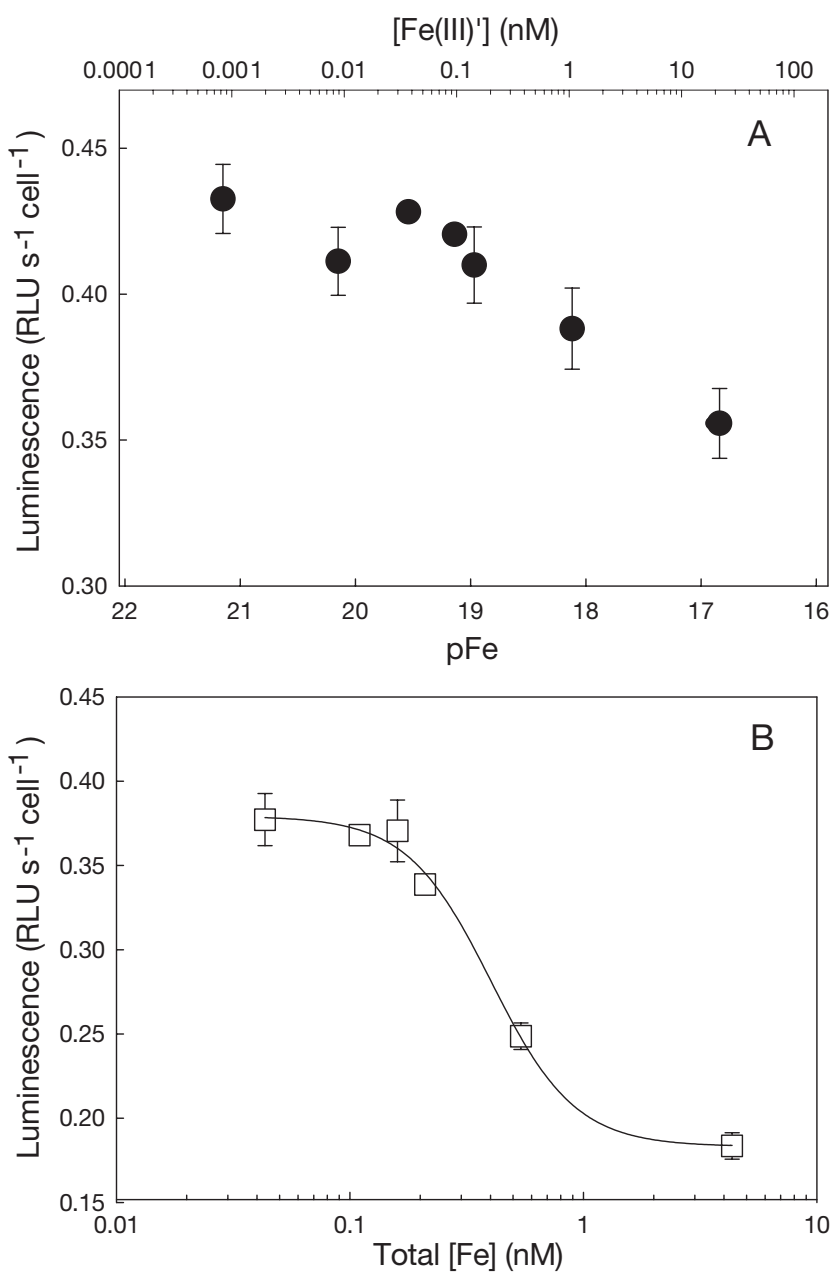

Fig. 1. Dose-response characterization of the Fe bioreporter Pseudomonas putida FeLux in bacterium growth enriched seawater, artificial seawater (BESAW) medium. (A) Doseresponse in the trace-metal-buffered BESAW medium. Regression analysis extending from $\mathrm{pFe} 16.84$ (Fe(III)' = $215 \mathrm{nM})$ and $\mathrm{pFe} 19.54\left(\mathrm{Fe}(\mathrm{III})^{\prime}=43 \mathrm{pM}\right)$ is represented $\left(\mathrm{r}^{2}=\right.$ 0.994 ; slope $=0.0271$ and $y$-intercept $=-0.1023)$. (B) Bioavailable Fe level (relative to total Fe concentrations) estimated with the $P$. putida bioreporter in BESAW medium supplemented with Vibrio natriegens PWH3a lysate. Cells preconditioned in Fe-deficient BESAW medium were used to inoculate Fe-free BESAW medium amended with increasing amounts of bacterial lysate. RLU: relative light unit. Error bars $(\mathrm{n}=9$, \pm SD) not shown where smaller than symbol size

sent in the dissolved fraction of $V$. natriegens PWH3a lysate was ca. 3 orders of magnitude more available to our bioreporter strain than $\mathrm{Fe}$ in the trace-metalbuffered BESAW medium. The dose-response elicited by the addition of $\mathrm{Fe}$ in the form of bacterial lysate was dramatically greater than when Fe source was provided as Fe-EDTA complex (Fig. 2). Light production decreased by a factor of 2 between the treatment amended with $0.16 \mathrm{nM} \mathrm{Fe-lysate} \mathrm{mixture} \mathrm{and} \mathrm{the} \mathrm{full}$ lysate treatment (ca. $4.33 \mathrm{nM}$ of Fe), while it decreased only $20 \%$ between pFe 19.54 and 16.84 treatments. 


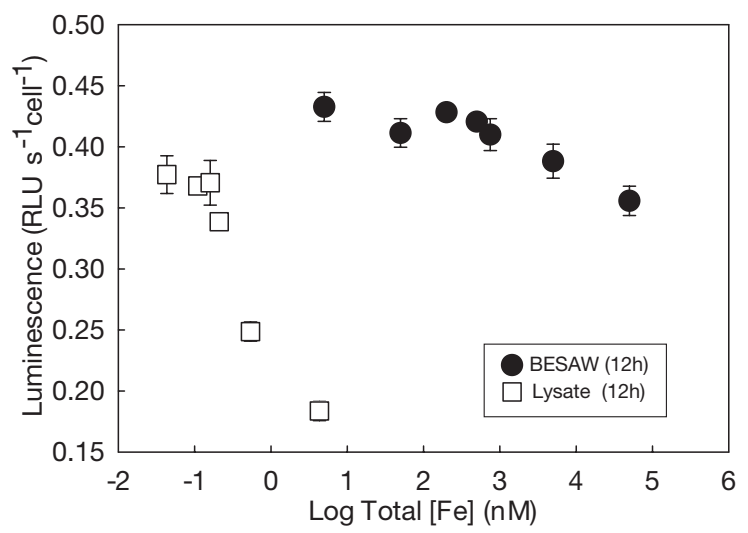

Fig. 2. Dose-response of Pseudomonas putida FeLux in both Fe-EDTA- and lysate-supplemented BESAW medium. Fe concentrations are reported as total concentrations of Fe to allow comparison between treatments. Bioluminescence production was measured following $12 \mathrm{~h}$ of incubation and normalized to the number of bioreporter cells $\mathrm{ml}^{-1}$. Error bars are $\pm \mathrm{SD}$ between replicates $(\mathrm{n}=3)$ and not shown where smaller than symbol size

\section{Fe assimilation from lysates}

The rate of Fe assimilation by the bioreporter cells from the Vibrio natriegens PWH3a lysates was measured to investigate the relationship between acquired Fe and light production (Fig. 3). Short-term Fe uptake rates did not exhibit saturation characteristics due to limitations in the Fe concentration of cell lysates. Over the range of experimental concentrations tested, the increase in short-term ${ }^{55} \mathrm{Fe}$ uptake rates was directly proportional to $\mathrm{Fe}$ concentrations in the lysateamended treatments ( $\log$ uptake rate $=1.218 \times 10^{-23}+$ $6.534 \times 10^{-21} \log$ total Fe; $\mathrm{r}^{2}=1$; Fig. 3A). This result suggests that, within the range of concentrations tested, Fe assimilated by bioreporter cells was directly correlated to the external concentrations of Fe and thus that maximal velocity of transport was not reached.

A comparison between uptake kinetics and bioreporter luminescent response (i.e. high-affinity transport systems expression) is presented in Fig. 3B. Over the range of concentrations tested, the bioluminescent signal produced by Pseudomonas putida FeLux decreased as ${ }^{55} \mathrm{Fe}$ uptake rates increased. This suggests a strong correlation (inverse) between bioluminescent signal and Fe assimilation, and as such validates the use of $P$. putida FeLux to estimate the available fraction of $\mathrm{Fe}$ in the extracellular environment. The luminescent signal was saturated for uptake rates lower than $1.02 \times 10^{-21}\left( \pm 2.41 \times 10^{-23}\right)$ as no significant differences were observed between these 3 treatments (ANOVA, p > 0.05). However, for these treatments, ${ }^{55} \mathrm{Fe}$ uptake rates decreased linearly
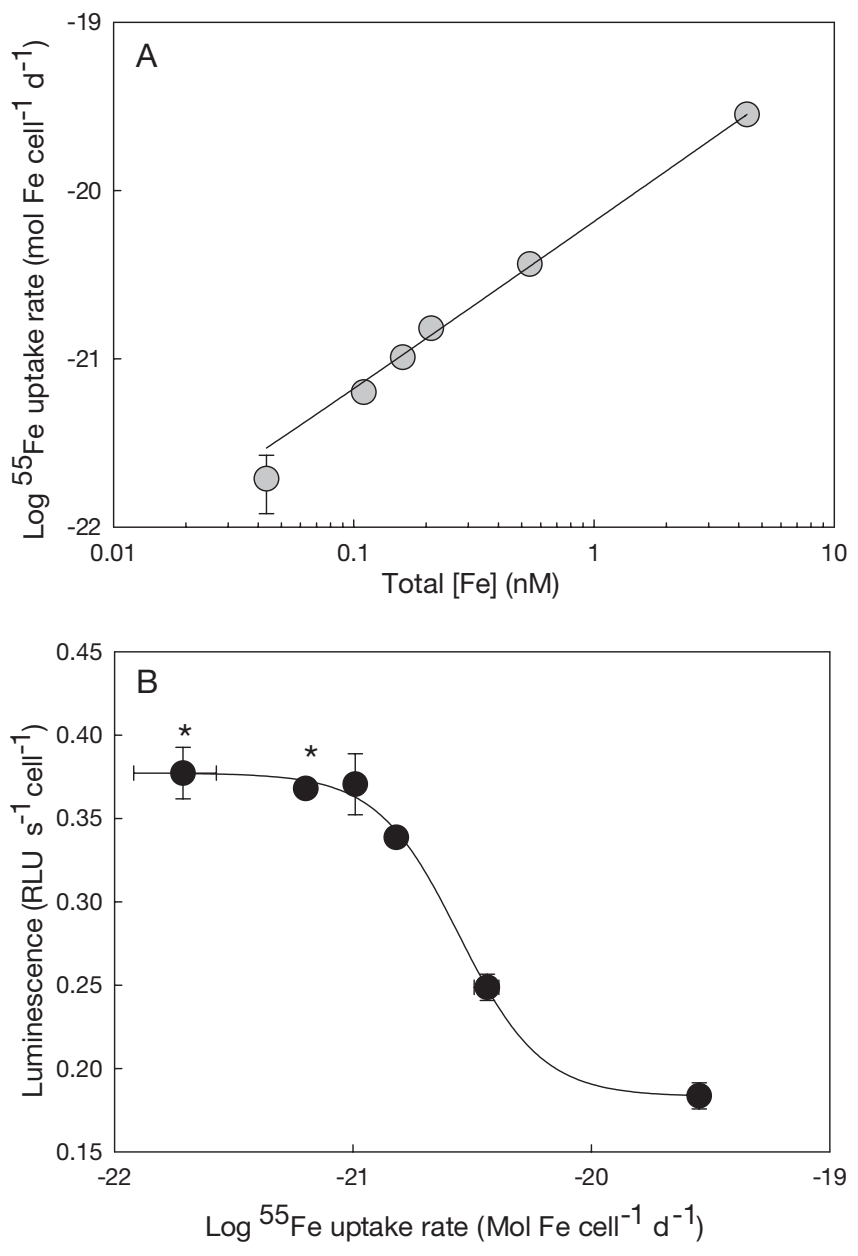

Fig. 3. Uptake of Fe from Vibrio natriegens PWH3a lysate by Pseudomonas putida FeLux. (A) Fe uptake rate as a function of total $\mathrm{Fe}$ concentrations in lysate-supplemented BESAW $\left(\mathrm{r}^{2}=1, \log\right.$ uptake rate $=1.218 \times 10^{-23}+6.534 \times 10^{-21} \log$ total Fe). Error bars are \pm SD between replicates $(n=3)$ and are not shown where smaller than the symbol size. (B) Comparison of Fe bioavailability with Fe uptake. The 4-parameter logistic function (linear; $\mathrm{r}^{2}=0.999$ ) characterizing the relationship between these 2 parameters as determined by using Sigma-plot software (vers. 9, SPSS) is represented. Values marked with an asterisk were not significantly different from one another.

All other values showed significant differences $(p<0.05)$

although Fe-transport systems were fully derepressed. Luminescence production also appeared quenched by our highest Fe treatment.

\section{Characterization of siderophores}

Extracellular Fe-ligand complexes isolated from the supernatant of both bacterial strains were examined with CAS assay. For both strains, the Fe-binding properties of crude siderophore extracts were confirmed visually by TLC analyses. Assuming that these 
siderophores bound $\mathrm{Fe}$ in 1:1 ratios, the cultures of Vibrio natriegens. PWH3a and Pseudomonas putida FeLux yielded total Fe-complexing concentrations of 9.25 and $12.00 \mu \mathrm{M}$, respectively, in the final extract. These siderophores will be referred to as 'cat1' ( $V$. natriegens ligands) and 'cat2' ( $P$. putida FeLux ligands). Both siderophore extracts yielded results below the detection limits of the Csaky test, implying that hydroxamate-type binding moieties were absent. In the Rioux assay, concentrations of $>50$ and $40.9 \mu \mathrm{m}$ catechols were observed for $V$. natriegens PWH3a and $P$. putida FeLux, respectively. The ratio of Rioux to CAS reactants ([catechol moieties]/[total deferrated ligands]) was $\sim 3$ for cat2, suggesting that this extract may be dominated by tricatecholate siderophore(s). cat1 also reacted positively with the Rioux assay but the concentration of catechols as in excess of the 3:1 (Rioux:CAS) predicted for tricatecholates, suggesting some other compounds (e.g. phenolics) that reduce Fe at low $\mathrm{pH}$ may have been present in the supernatant of $V$. natriegens cultures (Granger \& Price 1999).

\section{Assessment of siderophore bioavailability}

The bioavailability of the siderophores to the Pseudomonas putida FeLux bioreporter was examined in a separate set of experiments and compared to the bioavailability of inorganic Fe and Fe-DFB complex (Fig. 4). The concentration of bioavailable $\mathrm{Fe}$ in BESAW medium amended with inorganic $\mathrm{Fe}\left(\mathrm{FeCl}_{3}\right)$ was not significantly different from BESAW medium supplemented with Fe-EDTA complex corresponding to a pFe level of 18.12 ( $t$-test, $\mathrm{p}>0.05$ ). DFB addition

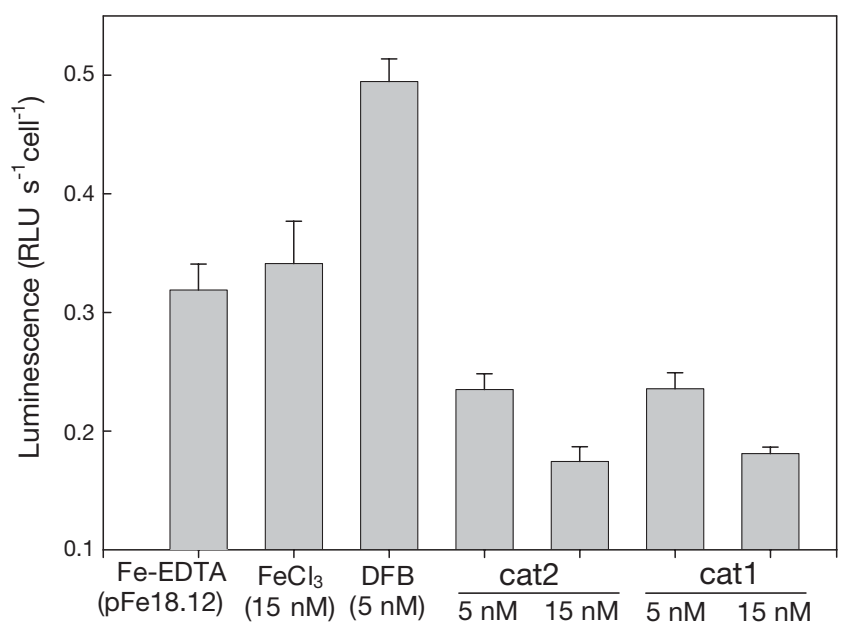

Fig. 4. Comparison of the bioavailability of Fe in presence of various ligands, including the siderophores produced by Vibrio natriegens and Pseudomonas putida FeLux (cat1 and cat2, respectively). Error bars are $+\mathrm{SD}$ between replicates $(n=3)$

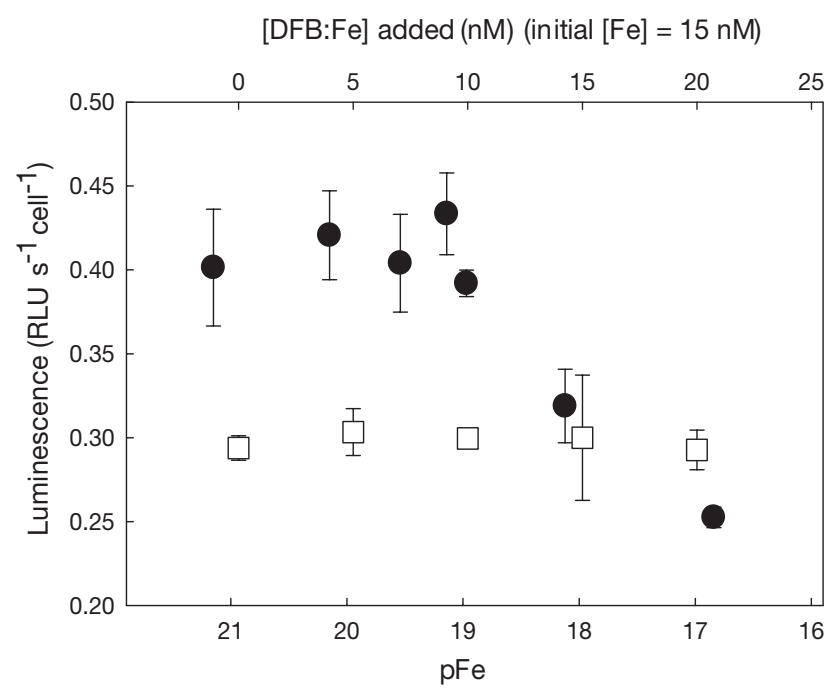

Fig. 5. Determination of the impact of desferrioxame B (DFB) on bioavailable Fe pool. Dose-response characterization of the Fe bioreporter Pseudomonas putida FeLux in the tracemetal-buffered BESAW medium (๑). Cells were prepared as described in Fig. 2. () Bioavailable Fe level predicted from $P$. putida FeLux bioreporter cells luminescence analyses in BESAW medium supplemented with equimolar Fe:DFB complex. Cells preconditioned in Fe-deficient BESAW medium ( $\mathrm{pFe} 21.15)$ were used to inoculate BESAW medium $\left(\left[\mathrm{FeCl}_{3}\right]=\right.$ $15 \mathrm{nM}$, EDTA omitted) supplemented with increasing amounts of Fe:DFB complex $(\mathrm{Fe}=\mathrm{DFB}=5,10,15$ and $20 \mathrm{nM})$. Fe concentrations are reported as total concentration of $\mathrm{Fe}$ and DFB added to allow comparison between treatments. Control treatment was not amended with Fe:DFB complex (0 $\mathrm{nM}$ ) and represent the bioavailable level of Fe in presence of $15 \mathrm{nM}$ of inorganic Fe. Bioluminescence production was measured following $12 \mathrm{~h}$ of incubation and normalized to the number of bioreporter cells $\mathrm{ml}^{-1}$. Error bars are \pm SD between replicates $(\mathrm{n}=3)$ and not shown where smaller than symbol size. $\mathrm{pFe}$ values computed for each DFB:Fe amendedtreatments are reported in Table 1

resulted in a significantly higher light production relative to the inorganic Fe treatment ( $t$-test, $p=0.003$ ). Light production from bioreporter cells grown in the medium amended with DFB corresponded to the saturation range of the calibration curve (i.e. pFe > 19.54), suggesting that high-affinity systems were completely derepressed. This result confirms that DFB complexed $\mathrm{Fe}$ is not available to the bioreporter.

The impact of DFB on Fe availability was further confirmed in a set of experiments in which increasing DFB concentrations were added as DFB:Fe complexes (1:1 molar ratio) to a BESAW medium supplemented with $15 \mathrm{nM}$ of $\mathrm{FeCl}_{3}$ (Fig. 5). No significant variation in the bioluminescent response (ANOVA, p > 0.05; Dunnett's test, $\mathrm{p}>0.05)$ was observed between Fe(III):DFBamended treatments compared to the unamended control. For all treatments, the bioluminescent signals fell into the linear range of the calibration curve, 
Table 2. Evaluation of the impact of desferrioxame B (DFB) addition on the bioluminescent signal of Pseudomonas putida FeLux. pFe values reported here represent the mean value $( \pm \mathrm{SD})$ of the $\mathrm{pFe}$ determined with Sigma-Plot (version 9.0, SPSS) 'Plot equation' function for each replicate $(\mathrm{n}=3$ for each treatment) using the regression analysis performed in the linear range of the calibration curve in the trace-metalbuffered BESAW medium. For comparison with Fig. 5, treatments are designated as the total concentration of $\mathrm{FeCl}_{3}$ and DFB added

\begin{tabular}{|lccc|}
\hline Treatment & Total Fe (nM) & DFB $(n M)$ & Inferred pFe \\
\hline 0 & 15 & 0 & $17.95 \pm 0.05$ \\
5 & 20 & 5 & $18.01 \pm 0.09$ \\
10 & 25 & 10 & $17.99 \pm 0.03$ \\
15 & 30 & 15 & $17.89 \pm 0.42$ \\
20 & 35 & 20 & $17.94 \pm 0.10$ \\
\hline
\end{tabular}

enabling us to determine the concentrations of bioavailable Fe (expressed as $\mathrm{pFe}$ ) for these treatments (Table 2). In all treatments, inferred bioavailable concentrations were not significantly different than that of the pFe 18.12 treatment (ANOVA, p > 0.05). These data demonstrate that DFB effects on Fe assimilation and bioreporter light production are a direct response to perceived bioavailable $\mathrm{Fe}$ in the extracellular environment (i.e. Fe complexation by DFB when DFB is in excess). Moreover, the consistency of the results (i.e. $15 \mathrm{nM} \mathrm{FeCl}_{3} \sim 10^{-18.12} \mathrm{M} \mathrm{Fe}^{3+} \sim \mathrm{Fe}(\mathrm{III})^{\prime}=1.63 \mathrm{nM}$ ) highlights the reproducibility and sensitivity of the bioreporter tool.

In contrast to DFB-amended treatments, addition of either bacterial siderophore extract resulted in a significant decrease in bioluminescent signal relative to treatments amended with inorganic Fe (Tukey-HSD test, $\mathrm{p}<0.001)$. The results suggest that siderophore addition significantly increased Fe availability compared to the inorganic Fe treatment. All siderophoresupplemented treatments were at the lower limit of the linear range of the calibration curve (ca. pFe 16.84). No significant difference was observed between treatments amended with similar levels of cat1 and cat2 (Tukey-HSD test, p > 0.05 for both 5 and $15 \mathrm{nM}$ additions). This suggests that Vibrio natriegens siderophores were available to Pseudomonas putida FeLux. Slight but significant decreases in light production per cell were observed upon addition of $15 \mathrm{nM}$ siderophore compared to the treatments amended with $5 \mathrm{nM}$ of siderophore $(t$-test, $\mathrm{p}=0.003$ [cat1 $5 \mathrm{nM}$ - cat1 $15 \mathrm{nM}$ ]; $\mathrm{p}=0.004$ [cat2 $5 \mathrm{nM}$ - cat2 $15 \mathrm{nM}$ ]). However, light production was never completely 'switched off', suggesting that a basal level of activity of the highaffinity transport systems was not repressed during the $12 \mathrm{~h}$ assay.

\section{DISCUSSION}

Two main conclusions can be drawn from this study. First, independent lines of evidence are presented which validate the use of the Pseudomonas putida FeLux bioreporter as a quantitative tool for estimating the biological availability of Fe in marine medium. The 2 parameters used in this study to estimate Fe bioavailability-bioluminescent signal and Fe uptake-are strongly correlated. Light production (i.e. the expression of high-affinity transport systems) from P. putida FeLux decreased as assimilation rates increased, suggesting a tight relationship between Fe acquisition and the luminescent response from this bioreporter strain. Furthermore, the results demonstrate the suitability of our bioreporter strain to discriminate across ranges of bioavailability of various Fe-organic complexes. Using the bioluminescent response of $P$. putida FeLux, we were able to rank the Fe sources tested here in a decreasing order of bioavailability: Fe-cat1 = Fe-cat2 > inorganic $\mathrm{Fe}\left(\mathrm{FeCl}_{3}, 15 \mathrm{nM}\right)=$ inorganic $\mathrm{Fe}$ species from EDTA-buffered treatment ( $\mathrm{pFe} 18.12, \mathrm{Fe}(\mathrm{III})^{\prime}=$ 980 pM) > Fe:DFB. Lastly, results from Fe(III):DFB amended treatments demonstrate that the bioluminescent response is impacted by the bioavailable Fe concentration and not the total dissolved Fe concentration in the extracellular environment. Taken together, our results therefore support the conclusion that the bioreporter P. putida FeLux could be a valuable tool for estimating variations in the bioavailability of naturally occurring Fe-ligand complexes in marine systems.

As suggested in Poorvin et al. (2004), the present study also confirms that viruses infecting prokaryotes may play a crucial role in planktonic Fe regeneration. Both the bioluminescent reporter signal and ${ }^{55} \mathrm{Fe}$ assimilation rates of the bioreporter cells provided a dosedependent response to increasing Fe from the dissolved $(<0.2 \mu \mathrm{m})$ fraction of Vibrio natriegens lysate. In addition, these results suggest that Fe from the lysis products enters the bioreporter cells via multiple transporters, as ferric uptake regulator (FUR)-controlled high-affinity systems can be repressed (as demonstrated by reduced light production) while transport velocities continue to increase. Given the energetic cost of high-affinity $\mathrm{Fe}$ transport system production, multiple acquisition systems may be advantageous in Fe-limited environments. Finally, Fe released from $V$. natriegens lysate and presented to the bioreporter resulted in a more significant decrease in the bioluminescent signal than when the bioreporter was fed with its own siderophores. As discussed below, our results support the hypothesis that Fe released from lysates is highly bioavailable. Given that these lysates contain a diverse collection of bound Fe sources, Fe released from virus-mediated lysis may be acquired 
through specific (e.g. outer membrane receptors) and nonspecific (e.g. porin channels) transport pathways (Winkelmann 1990).

\section{Determination of Fe bioavailability from virus lysates}

Results from the bioreporter and ${ }^{55} \mathrm{Fe}$ assimilation assays demonstrated that Fe present in the dissolved phase of Vibrio natriegens lysates was significantly (ANOVA, p > 0.05) more available to Pseudomonas putida FeLux than Fe present in Fe-EDTA buffered medium. These results are consistent with recent reports (Poorvin et al. 2004). Using ${ }^{55} \mathrm{Fe}$ uptake assays and the marine bacterium $V$. harveyi as a model organism, Poorvin et al. (2004) also observed that Fe released from the dissolved fraction of virus-mediated bacterial lysis was more readily assimilated than Fe complexed to EDTA.

Our inability to saturate $\mathrm{Fe}$ assimilation rates for Pseudomonas putida FeLux in the lysate-amended treatments while repressing light production indicates that Fe complexes released from virus-mediated lysis entered the cells through more than one transport systems, i.e. both non-specific (low-affinity system) and specific routes (high-affinity systems) (Winkelmann 1990). It has been reported that high concentrations of Fe-ligands may contribute to a diffusion-like behavior while transport systems start operating inefficiently or are bypassed (Winkelmann 1990). This hypothesis is supported by the comparison of uptake rates to bioreporter bioluminescent response (i.e. high-affinity transport systems expression). Through the range of concentrations tested, the bioluminescent response was not linear, while the ${ }^{55} \mathrm{Fe}$ uptake rate increased linearly. An indirect linear relationship between light production and Fe concentrations was only observed for the 3 intermediate treatments (ca. 0.16, 0.21 and $0.54 \mathrm{nM}$ ). High-affinity transport systems reached their maximal level of expression at total Fe $(<0.2 \mu \mathrm{m})$ concentrations lower than $0.21 \mathrm{nM}$, and were fully repressed (characteristic of Fe-replete conditions) in the 'full lysates' treatment (ca. $4.33 \mathrm{nM}$ ). These data highlight one limitation of bioreporters as a tool: the relatively limited dynamic range through which they can be used as a quantitative tool (Durham et al. 2002). However, they also demonstrate that the linear portion of the doseresponse occurs within the range of dissolved organic Fe concentrations commonly found in aquatic environments (Rue \& Bruland 1995, Wu \& Luther 1995), confirming that $P$. putida FeLux bioreporter is suitable to assess Fe bioavailability in HNLC environments.

The ${ }^{55} \mathrm{Fe}$ assimilation rates also provide important data that suggest Fe-uptake rates were directly pro- portional to extracellular Fe concentrations over the range of concentrations tested. Therefore, although the high-affinity Fe transport systems were fully derepressed, Fe assimilation rates were lower in the Fe-limited treatments. Furthermore, although highaffinity transport systems were reduced to minimal expression level in the higher range of concentrations tested, Fe assimilation increased linearly with higher ${ }^{55} \mathrm{Fe}$ concentrations. If transport rates were only influenced by the density of FUR-regulated membrane receptors (and thus light production), uptake rates should have followed Michaelis-Menten saturation kinetics within the range of Fe concentrations tested. Such a saturation curve was not observed, even though we know FUR-regulated transport was repressed. This highlights the difficulty of characterizing Fe transport in systems where multiple transporters (and multiple Fe-complexes) persist. Taken together, these results suggest that Fe permeated the cells through pathways that were not FUR-regulated.

Previously size fractionation studies have shown that the virus-mediated lysis of Vibrio natriegens cells releases Fe predominantly in the $<3 \mathrm{kDa}$ size-fraction (Poorvin et al. 2004). Previous studies with cyanobacteria (Wang \& Dei 2003) have also demonstrated that Fe present in the $<1 \mathrm{kDa}$ size fraction of seawater was assimilated ca. 1.7 times faster than Fe-complexes of higher molecular weight $(1 \mathrm{kDa}$ to $0.2 \mu \mathrm{m})$. It is therefore plausible that a fraction of the organic Fecomplexes released from virus-mediated lysis are small enough to pass through membrane porins (size limit $200 \mathrm{Da}$, Andrews et al. 2003) and constitute a non-negligible source of bioavailable Fe. The available literature data documenting 'low-affinity' Fe transport systems are scarce, and mainly focus on the pathogenic bacteria Escherichia coli and Helicobacter pylori (Velayudhan et al. 2000, Andrews et al. 2003). Several potential transport pathways, including outermembrane receptors specific to other metals or cations, and nonbiologically driven Fe binding to the cell surface, have been suggested; however, a low-affinity transport system has not been identified to date (Andrews et al. 2003). Recent experiments on the bacterium $H$. pylori suggest that low-affinity Fe uptake systems are not sufficient to support optimal growth even in the presence of high concentration of $\mathrm{Fe}$ (Velayudhan et al. 2000).

Previous reports also suggest that Fe-uptake systems involved in the acquisition of Fe from heterologous ferric-binding ligand complexes are differentially regulated relative to those involved in the acquisition of Fe from cognate siderophores (Venturi et al. 1995, Ratledge \& Dover 2000). It has been suggested that an Fe-acquisition system involving an outer-membrane ferric reductase associated to an Fe(II)-salicylate shut- 
tle could be a common feature in bacteria (Ratledge \& Dover 2000). Such a pathway of Fe acquisition would be less specific than the acquisition system involved in the uptake of cognate siderophores, and may allow bacteria to acquire Fe bound to a wide range of organic ligands.

These results suggest that Fe sources present in virus-mediated lysates are highly available to heterotrophic bacteria and may be internalized into microbial cells through several routes. Such a transport strategy is plausible owing to the diversity of the potential Fe sources in natural systems. If Pseudomonas putida FeLux (or other) bacterial cells relied only on highly specific high-affinity transport systems, cells would have to produce a large variety of specific outer membrane receptors. As such, bacterial cells would be at a competitive disadvantage given the energetic costs required to produce and maintain these systems (Griffin et al. 2004). As organic Fe-ligands are often found in excess in surface seawater (Rue \& Bruland 1995, Wu \& Luther 1995), we speculate that microorganisms may employ multiple Fe-acquisition strategies in oceanic environments.

\section{Specificity of Fe-siderophore acquisition and cross-utilization}

Under our experimental conditions, the bioluminescent signal was higher when Fe was provided as inorganic Fe than as an Fe(III)-catechol complex (Fig. 4). These results suggest that cells require the activation of the high-affinity transport systems to internalize inorganic Fe. Although no inorganic Fe(III)-transporter has been found to date in the outer membrane of heterotrophic bacteria (Granger \& Price 1999), inorganic Fe may be internalized into cells as Fe(III)siderophore complexes through outermembrane receptors (Winkelmann 1990) or through a broader Fe(III) exchange mechanism also requiring production of siderophores (Stintzi et al. 2000). Our results agree with previous reports which suggest that inorganic Fe(III)-acquisition by heterotrophic bacterial cells requires activation of high-affinity transport systems and the production of siderophores (Granger \& Price 1999, Guan et al. 2001). Indeed our results confirm that the bioluminescence signal is indirectly correlated to the estimated concentration of bioavailable Fe in the environment of the bioreporter and not to the total Fe concentration.

At comparable concentrations, Fe released from Vibrio natriegens lysates appeared more efficient at satiating bioreporter cells requirements than Fe from Fe(III)siderophore complexes. This result supports our hypothesis that Fe released from virus-mediated lysis enters cells through transport systems other than the specific outer-membrane receptors. In the case of siderophores, high-affinity systems need to remain active to maintain production of outer-membrane receptors (Andrews et al. 2003). Fe(III)-siderophore complexes are too large to be internalized by passive diffusion or non-specific transport in Gram-negative bacteria (Andrews et al. 2003). Two main mechanisms for Fe(III)-siderophore transport have been previously described in Gram-negative bacteria: one specific, involving ligand exchange at the level of the outermembrane receptor, and a second non-specific with a siderophore shuttle mechanism in which ligands pass serially through a channel with an Fe(III) exchange between siderophores (Wilhelm \& Trick 1994, Stintzi et al. 2000). Although Fe acquisition through the ligand exchange mechanism has been shown to mediate cross-utilization of exogenous siderophores (Stintzi et al. 2000), it has also been shown that some outer membrane receptors recognize Fe-siderophore complexes produced by other species (Winkelmann 1990). The lack of significant difference observed in the bioluminescent signal between the cat1- and cat2-amended treatments suggests that in both cases high-affinity transport systems were probably involved in Fe acquisition. Although both siderophores were available to Pseudomonas putida FeLux, the luminescent signal remained higher than observed in the lysate-amended treatments. These results suggest that a basal expression of the high affinity-transport systems was required to maintain the production of transport components and may reflect a homeostatic balance between the cost of the production of such high-affinity systems and the energy required to sustain cell metabolic functions (Andrews et al. 2003).

Interestingly, the bioluminescent signal was never completely repressed by the addition of the most available form of Fe, the lysates. This observation suggests that high-affinity transport systems, and probably other FUR-regulated genes, are not a 'fully on/off' system. McHugh et al. (2003) observed differences in the level of derepression between genes involved in $\mathrm{Fe}$ acquisition at identical Fe concentrations. Fe-enterobactin uptake genes (such as the fepA acquisition system used in our bioreporter) were among the most weakly derepressed, indicating that such a system is controlled more by cellular Fe status than by the acquisition apparatus itself. Thus, we speculate that the background bioluminescent signal may reflect the basal level of high-affinity transport system expression required to sustain the increased Fe demand resulting from the induction of Fe-containing protein synthesis (e.g. respiratory proteins). Such maintenance of highaffinity system expression, even under suboptimal Fe conditions, may also reflect a compromise between 
maintaining assimilation rates and reducing transporter proteins which also act as targets for bacteriophages and antibiotics (Andrews et al. 2003).

In contrast to cat 2 and the exogenous cat1, the fungal siderophore DFB sequestered Fe away from the bioreporter cells. Although it has been shown that DFB has a toxic effect on eukaryotic cells (Fukuchi et al. 1994, Leardi et al. 1998), we have demonstrated that this is not the case for our heterotrophic bioreporter (Fig. 5). Our results do demonstrate that Fe:DFB complex were not available to Pseudomonas putida FeLux, probably because DFB was not recognized by the outer membrane receptors (or Fe(III)-ligand exchange mechanism). Although results based on a single model organism must be extrapolated with caution, most studies on aquatic systems also suggest that the fungal siderophore DFB reduces the bioavailability of Fe to the planktonic community (Mioni et al. 2003, Weaver et al. 2003, Eldridge et al. 2004) and that the transport kinetics of Fe:DFB complexes are not sufficient to sustain growth (Hutchins et al. 1999b). However, Fe acquisition from Fe:DFB complexes is still a source of debate as it has also been suggested that phytoplankton communities can access to at least a fraction of this chelated Fe (Maldonado \& Price 1999) and that the diatom Phaeodactylum tricornutum could reduce Fe:DFB complexes by reductases located on the cell surface and subsequently internalize the reduced Fe (Soria-Dengg \& Horstmann 1995). The utilization of the siderophore DFB as a carbon source has been recently reported for 1 isolated soil bacterium, a Rhizobium loti-like organism (Pierwola et al. 2004), but could represent an adaptation to its ecological niche since actinomycetes (those that produce DFB) are relatively abundant in soil environments. To date, only 1 marine siderophore (desferroxamine G) closely related to DFB has been fully characterized, and it is produced by a symbiotic Vibrio strain not commonly found as free-living cells in the water column (Martinez et al. 2001). Indeed, one may presume that producing receptors specific to such a rarely occurring trihydroxamate siderophore would be needlessly expensive for natural bacterioplankton.

Although the cross-availability of various siderophores to diverse aquatic organisms has been documented for laboratory culture or enclosed-seawater samples (Trick 1989, Granger \& Price 1999, Hutchins et al. 1999a, Guan et al. 2001, Weaver et al. 2003), the artificial conditions of these incubation experiments might be a source of bias. Indeed, it has been argued that relying on siderophores as a sole Fe source may be inefficient and energetically expensive in an aquatic environment due to the strong probability of a diffusion of the siderophores away from the cell (Völker \& Wolf-Gladrow 1999), especially if other microbes could exploit these newly formed complexes (Griffin et al. 2004). The cost of siderophore excretion by an isolated heterotrophic cell is also metabolically expensive, especially where organic carbon may also be limiting (Kirchman et al. 2000). Models predict that Fe acquisition through freely diffusible siderophores may be an efficient strategy in oceanic environment only when the concentration of organic ligands in the surrounding environment is high enough to allow the bacteria cell to use siderophores (cognate and xenosiderophores) excreted by other cells (Völker \& Wolf-Gladrow 1999).

One way to counter this problem is to produce compounds with reduced diffusive potential in aquatic systems. Wilhelm \& Trick (1994) proposed such a model, where production of relatively hydrophobic catecholtype siderophores (like those discussed in this study) allows cells to maintain a surface concentration of active chelates. More recently Martinez et al. (2003) identified cell-associated amphiphilic chelators in marine bacterial samples and suggested that this cell association could be a strategy to counter siderophore diffusion in the oceanic environment.

\section{CONCLUSIONS}

Results from this study reinforce the view that Fe released from virus-mediated lysis should be an important source of bioavailable Fe to bacterioplankton (Poorvin et al. 2004). Increasing evidence suggests that viruses play a pivotal role in Fe transfer in aquatic environments (Gobler et al. 1997, Wilhelm \& Suttle 2000, Poorvin et al. 2004). In the case of heterotrophic bacteria, the bioavailability of Fe in the lysates may be related to the high diversity of organic Fe species released through virus-mediated lysis. Considering the importance of viral lysis in nutrient regeneration, we speculate that $\mathrm{Fe}$ acquisition through molecular recognition pathways (i.e. siderophore-specific outer membrane receptor) might not be the main system used by microbial cells under ambient conditions. The relatively small size of bacterial cells and the miniaturization of microbial cells observed under Fe limitation (Eldridge et al. 2004) might enable them to rely on non-specific $\mathrm{Fe}$ pathways such as diffusion through porins or oxydo-reduction through outer-membrane ferric reductases. Such processes may explain why marine prokaryotes are able to sustain higher $\mathrm{Fe}$ assimilation rates and cell Fe:C quotas than eukaryotic phytoplankton (Tortell et al. 1999).

Acknowledgements. We thank Drs. P. L. Croot, and M. R. Twiss for comments and Dr. W. G. Sunda for assistance in defining the chemical speciation of the BESAW medium, and 3 anonymous reviewers for their constructive comments. This 
work was supported by NSF OCE-0002968 and NSF OCE9977040 to S.W.W., as well as by a University of Tennessee Center for Environmental Biotechnology Graduate Fellowship, a Ryan Kelley Memorial scholarship-International Women's Fishing Association 2003, and a Daniel Jouvance Award 'Recherches sur le plancton marin 2003' to C.E.M.

\section{LITERATURE CITED}

Andrews SC, Robinson AK, Rodriguez-Quiñones F (2003) Bacterial iron homeostasis. FEMS Microbiol Rev 27: 215-237

Arrieta JM, Weinbauer MG, Lute C, Gerhard JH (2004) Response of bacterioplankton to iron fertilization in the Southern Ocean. Limnol Oceanogr 49:799-808

Berges JA, Franklin DJ, Harrison PJ (2001) Evolution of an artificial seawater medium, improvements in enriched seawater, artificial water over the last two decades. J Phycol 37:1138-1145

Boyd PW (2004) Ironing out algal issues in the southern ocean. Science 304:396-397

Boye M, van den Berg CMG, de Jong JTM, Leach H, Croot P, de Baar HJW (2001) Organic complexation of iron in the Southern Ocean. Deep-Sea Res I 48:1477-1497

Breitbart M, Salamon P, Andresen B, Mahaffy JM, Segall AM, Mead D, Azam F, Rohwer F (2002) Genomic analysis of uncultured marine viral communities. Proc Natl Acad Sci USA 99:14250-14255

Butler A (1998) Acquisition and utilization of transition metal ions by marine organisms. Science 281:207-210

Church MJ, Hutchins DA, Ducklow HW (2000) Limitation of bacterial growth by dissolved organic matter and iron in the Southern Ocean. Appl Environ Microbiol 66:455-466

Corston R, Colman AM (eds) (2003) One-way analysis of variance. In: A crash course in SPSS for windows versions 10 and 11, 2nd edn. Blackwell Publishing, Malden, MA, p 74-82

Csaky TZ (1948) On the estimation of bound hydroxylamine in biological materials. Acta Chem Scand 2:450-454

Durham KA, Porta D, Twiss MR, McKay RML, Bullerjahn GS (2002) Construction and initial characterization of a luminescent Synechococcus sp. PCC 7942 Fe-dependent bioreporter. FEMS Microbiol Lett 209:215-221

Eldridge ML (2004) The effects of Fe on plankton in HNLC regions of the world's oceans. PhD dissertation, University of Tennessee, Knoxville, TN

Eldridge ML, Trick CG, Alm MB, DiTullio GR, Rue EL, Bruland KW, Hutchins DA, Wilhelm SW (2004) Phytoplankton community response to a manipulation of bioavailable iron in HNLC waters of he subtropical Pacific Ocean. Aquat Microb Ecol 35:79-91

Fuhrman JA (1999) Marine viruses and their biogeochemical and ecological effects. Nature 399:541-548

Fukuchi K, Tomoyasu S, Tsuruoka N, Gomi K (1994) Iron deprivation-induced apoptosis in HL-60 cells. FEBS Lett 350:139

Gillam AH, Lewis AG, Andersen RJ (1981) Quantitative determination of hydroxamic acids. Anal Chem 53: 841-844

Gledhill M, van den Berg CMG (1994) Determination of complexation of iron (III) with natural oorganic complexing ligands in seawater using cathodic stripping voltammetry. Mar Chem 47:41-54

Gledhill M, McCormack P, Ussher S, Achterberg EP, Mantoura RCF, Worsfold PJ (2004) Production of siderophore type chelates by mixed bacterioplankton populations in nutrient enriched seawater incubations. Mar Chem 88: 75-83

Gobler CJ, Hutchins DA, Fisher NS, Cosper EM, SañudoWilhelmy SA (1997) Release and bioavailability of C, N, P, $\mathrm{Se}$, and Fe following viral lysis of marine chrysophyte. Limnol Oceanogr 42:1492-1504

Granger J, Price NM (1999) The importance of siderophores in iron nutrition of heterotrophic marine bacteria. Limnol Oceanogr 44:541-555

Griffin AS, West SA, Buckling A (2004) Cooperation and competition in pathogenic bacteria. Nature 430:1024-1027

Guan LL, Kanoh K, Kamino K (2001) Effect of exogenous siderophores on iron uptake activity of marine bacteria under iron-limited conditions. Appl Environ Microbiol 67: 1710-1717

Hobbie JE, Daley RJ, Jasper S (1977) Use of nucleopore filters for counting bacteria by fluorescence microscopy. Appl Environ Microbiol 33:1225-1228

Hudson RJM, Morel FMM (1989) Distinguishing between extracellular and intracellular iron in marine phytoplankton. Limnol Oceanogr 34:1113-1120

Hutchins DA, Witter AE, Butler A, Luther GW (1999a) Competition among marine phytoplankton for different chelated iron species. Nature 400:858-861

Hutchins DA, Franck V, Brzezinski MA, Bruland K (1999b) Inducing phytoplankton iron limitation in iron-replete coastal waters with a strong chelating agent. Limnol Oceanogr 44:1009-1018

Hutchins DA, Campbell BJ, Cottrell MT, Takeda S (2001) Response of marine bacterial community composition to iron additions in three iron-limited regimes. Limnol Oceanogr 46:1535-1545

Keller MD, Bellows WK, Guillard RRL (1988) Microwave treatment for sterilization of phytoplankton culture media. J Exp Mar Biol Ecol 117:279-283

Kirchman DL, Meon B, Cottrell MT, Hutchins DA, Weeks D, Bruland KW (2000) Carbon versus iron limitation of bacterial growth in the California upwelling regime. Limnol Oceanogr 45:1681-1688

Leardi A, Caraglia M, Selleri C, Pepe S and 8 others (1998) Desferioxamine increases iron depletion and apoptosis induced by ara-C of human myeloid leukaemic cells. Br J Haematol 102:746-752

Lewis BL, Holt PD, Taylor SW, Wilhelm SW, Trick CG, Butler A, Luther GW (1995) Voltammetric estimation of iron(III) thermodynamic stability constants for catecholate siderophores isolated from marine bacteria and cyanobacteria. Mar Chem 50:179-188

Liu ZD, Hider RC (2002) Design of clinically useful iron(III)selective chelators. Med Res Rev 22:26-64

Maldonado MT, Price NM (1999) Utilization of iron bound to strong organic ligands by plankton communities in the subarctic Pacific Ocean. Deep-Sea Res II 46:2447-2473

Martinez JS, Haygood MG, Butler A (2001) Identification of a natural desferrioxamine siderophore produced by a marine bacterium. Limnol Oceanogr 46:420-424

Martinez JS, Carter-Franklin JN, Mann EL, Martin JD, Haygood MG, Butler A (2003) Structure and membrane affinity of a suite of amphiphilic siderophores produced by a marine bacterium. Proc Natl Acad Sci USA 100:3754-3759

McHugh JP, Rodriguez-Quiñones F, Abdul-Tehrani H, Svistunenko DA, Poole RK, Cooper CE, Andrews SC (2003) Global iron-dependent gene regulation in Escherichia coli-a new mechanism for iron homeostasis. J Biol Chem 278:29478-29486

Meyer JM, Hohnabel D (1992) Use of nitriloacetic acid (NTA) by Pseudomonas species through iron metabolism. Appl 
Microbiol Biotechnol 37:114-118

Mioni CE (2004) Using a bioluminescent bacterial bioreporter to assess iron bioavailability in the Oceans. $\mathrm{PhD}$ dissertation, University of Tennessee, Knoxville, TN

Mioni CE, Howard AM, DeBruyn JM, Bright NG, Twiss MR, Applegate BM, Wilhelm SW (2003) Characterization and field trials of a bioluminescent bacterial reporter of iron bioavailability. Mar Chem 83:31-46

Moore JK, Doney SC, Lindsay K (2004) Upper ocean ecosystem dynamics and iron cycling in a global three-dimensional model. Global Biogeochem Cycles 18:GB4028, doi:10.1029/20046B00220

Pakulski JD, Coffin RB, Kelley CA, Holder SL, Downer R, Aas P, Lyons MM, Jeffrey WH (1996) Iron stimulation of Antarctic bacteria. Nature 383:133-134

Pierwola A, Krupinski T, Zalupski P, Chiarelli M, Castignetti D (2004) Degradation pathway and generation of monohydroxamic acids from the trihydroxamate siderophore deferrioxamine B. Appl Environ Microbiol 70:831-836

Poorvin L, Rinta-Kanto JM, Hutchins DA, Wilhelm SW (2004) Viral release of iron and its bioavailability to marine plankton. Limnol Oceanogr 49:1734-1741

Price NM, Harrison GI, Herring JG, Hudson RJ, Nirel PMV, Palenik B, Morel FMM (1988) Preparation and chemistry of the artificial algal culture medium Aquil. Biol Oceanogr 6:443-461

Ratledge C, Dover LG (2000) Iron metabolism in pathogenic bacteria. Annu Rev Microbiol 54:881-941

Rioux C, Jordan DC, Rattray JBM (1983) Colorimetric determinatopn of catechol siderophores in microbial cultures. Anal Biochem 133:163-169

Rue EL, Bruland KW (1995) Complexation of iron(III) by natural organic ligands in the Central North Pacific as determined by a new competitive ligand equilibration/ adsorptive cathodic stripping voltammetric method. Mar Chem 50:117-138

Schwyn B, Neilands JB (1987) Universal chemical assay for the detection and dertermination of siderophores. Anal Biochem 160:47-56

Soria-Dengg S, Horstmann U (1995) Ferrioxamines B and E as iron sources for the marine diatom Phaeodactylum tricornutum. Mar Ecol Prog Ser 127:269-277

Stintzi A, Barnes C, Xu J, Raymond KN (2000) Microbial iron transport via a siderophore shuttle: a membrane ion transport paradigm. Proc Natl Acad Sci USA 97: 10691-10696

Sunda WG, Huntsman S (2003) Effect of pH, light, and temperature on Fe-EDTA chelation and Fe hydrolysis in seawater. Mar Chem 84:35-47

Editorial responsibility: Paul Harrison, Kowloon, Hong Kong SAR
Tortell PD, Maldonado MT, Price NM (1996) The role of heterotrophic bacteria in iron-limited ocean ecosystems. Nature 383:330-332

Tortell PD, Maldonado MT, Granger J, Price NM (1999) Marine bacteria and biogeochemical cycling of iron in the oceans. FEMS Microbiol Ecol 29:1-11

Trick CG (1989) Hydroxamate-siderophore production and utilization by marine eubacteria. Curr Microbiol 18: 375-378

Velayudhan J, Hughes NJ, McColm AA, Bagshaw J, Clayton CL, Andrews SC, Kelly DJ (2000) Iron acquisition and virulence in Helicobacter pylori: a major role for FeoB, a high-affinity ferrous iron transporter. Mol Microbiol 37: $274-286$

Venturi V, Weisbeek P, Koster M (1995) Gene regulation of siderophore-mediated iron acquisition in Pseudomonas, not only the Fur repressor. Mol Microbiol 17:603-610

Völker C, Wolf-Gladrow DA (1999) Physical limits on iron uptake mediated by siderophores or surface reductases. Mar Chem 65:227-244

Wang WX, RCH Dei (2003) Bioavailability of iron complexed with organic colloids to cyanobacteria Synechococcus and Trichodesmium. Aquat Microb Ecol 33:247-259

Weaver RS, Kirchman DL, Hutchins DA (2003) Utilization of iron/organic ligand complexes by marine bacterioplankton. Aquat Microb Ecol 31:227-239

Weinbauer MG (2004) Ecology of prokaryotic viruses. FEMS Microbiol Rev 28:127-181

Wilhelm SW, Suttle CA (1999) Viruses and nutrient cycles in the sea. BioScience 49:781-788

Wilhelm SW, Suttle CA (2000) Viruses as regulators of nutrient cycles in aquatic environments. In: Bell C, Brylinsky M, Johnson-Green P (eds) Microbial biosystems. Atlantic Canada Society for Microbial Ecology, Halifax, p 551-556

Wilhelm SW, Trick CG (1994) Iron-limited growth of cyanobacteria: multiple siderophore production is a common response. Limnol Oceanogr 39:1979-1984

Wilhelm SW, Trick CG (1995) Physiological profiles of Synechococcus (Cyanophyceae) in iron-limited continuous cultures. J Phycol 31:79-85

Winkelman G (1990) Specificity of iron transport in bacteria and fungi. In: Winkelman G (ed) Handbook of microbial iron chelates. CRC Press, Boca Raton, FL, p 65-105

Wommack KE, Colwell RR (2000) Virioplankton: viruses in aquatic ecosystems. Microbiol Mol Biol Rev 64:69-114

Wu J, Luther GW (1995) Complexation of Fe(III) by natural organic ligands in the Northwest Atlantic Ocean by a competitive ligand equilibration method and a kinetic approach. Mar Chem 50:159-77

Submitted: November 8, 2004; Accepted: September 5, 2005 Proofs received from author(s): December 2, 2005 